\title{
The Memory-Undermining Effect of Simulated Crime-Related Amnesia and Its Legal Implications: a Review
}

\author{
Ivan Mangiulli ${ }^{1,2} \cdot$ Paul Riesthuis ${ }^{1,2} \cdot$ Henry Otgaar ${ }^{1,2}$
}

Received: 24 September 2021 / Accepted: 9 December 2021 / Published online: 21 December 2021

(c) The Author(s) 2021

\begin{abstract}
Pretending to suffer from amnesia for a mock crime has been shown to lead to memory impairments. Specifically, when people are asked to give up their role of simulators, they typically recall fewer crime-relevant details than those who initially confess to a crime. In the current review, we amassed all experimental work on this subject and assessed the characteristics of the memory-undermining effect of simulated amnesia for a crime procedure (i.e., crime stimuli, simulating amnesia instructions, memory tests, and memory outcomes). We specifically focused on the effect that crime-related amnesia claims may have on offenders' final memory reports. Our review showed that simulators who initially claimed amnesia might paradoxically experience some sort of forgetting pertaining to crime-related information. This issue could likely lead to legal complications that need be taken into account in crime-related amnesia cases.
\end{abstract}

Keywords Crime-related amnesia $\cdot$ Malingering $\cdot$ Simulating amnesia effect $\cdot$ Memory impairments $\cdot$ Legal implications

"I woke up close to the corpses, both times, I do not remember that I killed them, but I do not exclude it. The nights before I was with them, I remember I slept but when I woke up, I was in a blood lake. We had oral intercourse. Then, I fell asleep. It seemed like hours had passed and when I woke up I was entirely covered in blood." These words were reported by N.I., a 52-year-old man sentenced to life imprisonment for having murdered two prostitutes in a small city nearby Naples, Italy. ${ }^{1}$ N.I., who did not have any previous criminal record, was caught after five years of police investigation. In 2015, after his arrest, despite admitting having met the victims, N.I. claimed not to remember anything related to the crimes he was suspected of. He claimed to have a "black hole" in his memory, an amnesic gap for having abused, tortured, and murdered two women.

In legal contexts, crime-related amnesia claims are not rare (e.g., Cima et al., 2002; Jelicic, 2018). Sometimes defendants or convicted perpetrators claim to be unable to recall information about serious crimes (e.g., homicide and sexual assault) they were accused of. Although populations

Ivan Mangiulli

ivan.mangiulli@kuleuven.be

1 Faculty of Law and Criminology, Leuven Institute of Criminology, Leuven, KU, Belgium

2 Maastricht University, Maastricht, the Netherlands can vary and field studies on crime-related amnesia have limitations (see for a thorough analysis: Evans, 2006), approximately one third of violent offenders claim memory loss for their deeds (see Table 1).

Crime-related amnesia can become a challenging matter to forensic psychiatrists and psychologists. As a matter of fact, in the absence of organic-related dysfunctions (e.g., brain injury, alcohol and drug intoxication; Goodwin, 1995; Parkin, 1999; Stout \& Farooque, 2008; Van Oorsouw et al., 2004), many scholars doubt the authenticity of crimerelated amnesia claims (Centor, 1982; Jelicic, 2018; Jelicic \& Merckelbach, 2007). Research has shown that people are overall quite good at recalling their own actions (Engelkamp et al., 1994; Symons \& Johnson, 1997), arguably implying that memory for committing a crime is highly likely to be retained. Also, emotional or traumatic events are usually better remembered than neutral ones (Kensinger \& Ford, 2020; McGaugh, 2006; McNally, 2003, 2007). For instance, Rubin et al. (2004) did not find any support for the idea that war veterans' trauma-related memories become less accessible over time. Thus, these reasons offer strong grounds for the position that offenders who claim amnesia for their deeds are just pretending to suffer from memory loss (e.g., Jelicic, 2018).

\footnotetext{
$\overline{1}$ This case-report reflects an actual Italian case. See: http://napoli. repubblica.it/cronaca/2015
} 
Table 1 Studies on offenders' claims of amnesia (i.e., partial or complete) reported in the literature

\begin{tabular}{|c|c|c|c|}
\hline Authors & Population & Sample size & Amnesic \\
\hline Hopwood and Snell (1933) & Security hospital patients & 100 & $78(78 \%)$ \\
\hline Leitch (1948) & $\begin{array}{l}\text { Murderers } \\
\text { (inmates) }\end{array}$ & 51 & $16(31 \%)$ \\
\hline Guttmacher (1955) & Unclear & 36 & $12(33 \%)$ \\
\hline O’Connell (1960) & Murderers & 50 & $20(40 \%)$ \\
\hline Tanay (1969) & Murderers & 53 & $37(70 \%)$ \\
\hline Bradford and Smith (1979) & Murderers & 30 & $28(93 \%)$ \\
\hline Lynch and Bradford (1980) & $\begin{array}{l}\text { Various offenders } \\
\text { (including non-violent) }\end{array}$ & 22 & $17(77 \%)$ \\
\hline Taylor and Kopelman (1984) & $\begin{array}{l}\text { Various offenders } \\
\text { (including non-violent) }\end{array}$ & 203 & $19(9 \%)$ \\
\hline Parwatikar et al. (1985) & Murderers & 105 & $24(23 \%)$ \\
\hline Gudjonsson et al. (1989) & $\begin{array}{l}\text { Murderers } \\
\text { (or attempted murders) }\end{array}$ & 16 & $9(56 \%)$ \\
\hline Gudjonsson et al. (1999) & Violent offenders & 37 & $18(49 \%)$ \\
\hline Spinelli (2001) & Murderers & 16 & $14(87 \%)$ \\
\hline Pyszora et al. (2003) & $\begin{array}{l}\text { Life-sentenced inmates } \\
\text { (1994 cohort) }\end{array}$ & 207 & $59(29 \%)$ \\
\hline Cima et al. (2003) & $\begin{array}{l}\text { Violent offenders } \\
\text { (psychiatric patients inmates) }\end{array}$ & 62 & $17(27 \%)$ \\
\hline Cima et al. (2004) & Inpatients & 308 & $72(23 \%)$ \\
\hline Evans et al. (2009) & Violent young offenders & 105 & $21(20 \%)$ \\
\hline Van Oorsouw and Cima (2007) & Inmates & 34 & $14(42 \%)$ \\
\hline Cima and Van Oorsouw (2013) & $\begin{array}{l}\text { Various offenders } \\
\text { (including non-violent) }\end{array}$ & 31 & $12(39 \%)$ \\
\hline Total & & 1466 & $487(33 \%)$ \\
\hline
\end{tabular}

The current table is adapted from Evans (2006). Percentages are shown rounded
With "malingered (or simulated) crime-related amnesia," forensic mental health experts refer to the deliberate simulation of memory loss surrounding a criminal act. Hopwood and Snell (1933) suggested that approximately $20 \%$ of the offenders who declared memory loss were actually malingerers. However, scholars have argued that such a rate could be much higher (e.g., Cima et al., 2002). Indeed, there are several reasons to believe that many offenders' memory loss claims are malingered. First, offenders may fake memory loss to obstruct police investigations, slowing down their course, thereby possibly affecting the trial proceedings (Tysse, 2005). Second, offenders might also hope that malingering memory loss might be beneficial to the outcome of their trial in an attempt to evade or minimize criminal responsibility (Tysse \& Hafemeister, 2006). Third, some offenders may pretend memory loss in an attempt to avoid possible painful conversations about their crime during psychiatric treatments (e.g., Cima et al., 2002). Relatedly, feelings of guilt and shame are not uncommon among violent perpetrators (e.g., murderers, sex offenders), which may likely decrease the motivation to come forward with actual, intimate details of the traumatic offense (e.g., Gudjonsson, 2003, 2006). Hence, malingering memory loss is an appealing strategy for many offenders.
Courts are oftentimes skeptical about crime-related amnesia claims. This is essentially due to two motives: First, rates of such claims are high, leading to the sentiment that the majority of the amnesic claims are unlikely. Consequently, and second, judges may suspect that a deliberate act of simulation could be hidden behind a memory loss claim in court. However, a critical factor that might be troublesome for the legal domain is related to the mnemonic consequences of the act of pretending to suffer from amnesia for a crime. That is, experimental studies have revealed that the intentional simulation of memory loss might impair memory for criminal experiences (Mangiulli et al., 2018b; Van Oorsouw \& Merckelbach, 2004). If so, statements might be become less reliable and detailed, thereby appearing less credible in court (e.g., Bell \& Loftus, 1988).

\section{The Memory-Undermining Effect of Simulated Amnesia}

Several experimental studies have examined the memoryundermining effect of simulated amnesia for a crime (see Table 2). In a nutshell, the standard procedure to study the memory-undermining effect of simulated crime-related 
Table 2 Studies on the memory-undermining effect of simulated amnesia reported in the literature

\begin{tabular}{|c|c|c|c|c|c|c|c|}
\hline \multirow[t]{3}{*}{ Authors } & \multirow[t]{3}{*}{ Sample size } & \multirow[t]{3}{*}{ Crime stimulus } & \multirow[t]{3}{*}{ Instruction given } & \multicolumn{4}{|c|}{ Simulating amnesia effect } \\
\hline & & & & \multicolumn{2}{|c|}{ Free recall } & \multicolumn{2}{|c|}{$\begin{array}{l}\text { Cued recall/ } \\
\text { other tasks }\end{array}$} \\
\hline & & & & $p$ & $d$ & $p$ & $d$ \\
\hline Christianson and Bylin (1999) & $\begin{array}{l}54 \\
(\mathrm{~S} n=25 ; \mathrm{C} n=29)\end{array}$ & Narrative story & Evading responsibility & $<0.05$ & n.r & $<0.05$ & n.r \\
\hline \multirow[t]{2}{*}{ Bylin $(2002)^{a, b}$} & $\begin{array}{l}55 \\
\left(\mathrm{~S} n_{l}=19 ; \mathrm{C} n=18\right)\end{array}$ & Narrative story & Appearing not guilty & $<0.001$ & 1.27 & $<0.05$ & n.r \\
\hline & $\begin{array}{l}55 \\
\left(\mathrm{~S} n_{2}=18 ; \mathrm{C} n=18\right)\end{array}$ & Narrative story & Appearing not guilty & $<0.001$ & 1.28 & $>0.05$ & n.r \\
\hline \multirow[t]{2}{*}{ Bylin and Christianson (2002) ${ }^{\mathrm{b}}$} & $\begin{array}{l}76 \\
\left(\mathrm{~S} n_{l}=19 ; \mathrm{C} n=19\right)\end{array}$ & Narrative story & Avoiding punishment & $<0.05$ & 1.11 & $<0.001$ & 0.73 \\
\hline & $\begin{array}{l}76 \\
\left(\mathrm{~S} n_{2}=19 ; \mathrm{C} n=19\right)\end{array}$ & Narrative story & Avoiding punishment & $>0.05$ & 0.30 & $<0.001$ & 1.05 \\
\hline Van Oorsouw and Merckelbach (2004) & $\begin{array}{l}61 \\
(\mathrm{~S} n=21 ; \mathrm{C} n=20)\end{array}$ & Mock crime & Minimizing responsibility & $<0.05$ & 0.77 & $<0.05$ & 0.66 \\
\hline Van Oorsouw and Merckelbach (2006) & $\begin{array}{l}60 \\
(\mathrm{~S} n=30 ; \mathrm{C} n=30)\end{array}$ & Mock crime & Evading responsibility & $<0.05$ & 0.72 & - & - \\
\hline Sun et al. (2009) (Exp. 1) & $\begin{array}{l}60 \\
(\mathrm{~S} n=20 ; \mathrm{C} n=20)\end{array}$ & Narrative story & Evading responsibility & $<0.0001$ & n.r & $<0.0001$ & n.r \\
\hline Sun et al. (2009) (Exp. 2) & $\begin{array}{l}46 \\
(\mathrm{~S} n=14 ; \mathrm{C} n=16)\end{array}$ & Narrative story & Evading responsibility & $<0.001$ & n.r & $<0.05$ & n.r \\
\hline Mangiulli et al. (2018b) & $\begin{array}{l}111 \\
(\mathrm{~S} n=37 ; \mathrm{C} n=37)\end{array}$ & Mock crime video & Evading punishment & 0.014 & 0.61 & 0.12 & 0.44 \\
\hline Romeo et al. $(2018)^{\mathrm{a}}$ & $\begin{array}{l}93 \\
(\mathrm{~S} n=31 ; \mathrm{C} n=31)\end{array}$ & Mock crime & Evading punishment & - & - & 0.08 & 0.44 \\
\hline Mangiulli et al. (2019a) (Exp. 1) & $\begin{array}{l}90 \\
(\mathrm{~S} n=30 ; \mathrm{C} n=30)\end{array}$ & Mock crime video & Evading punishment & 0.65 & 0.16 & 0.61 & 0.10 \\
\hline Mangiulli et al. (2019a) (Exp. 2) & $\begin{array}{l}150 \\
(\mathrm{~S} n=50 ; \mathrm{C} n=50)\end{array}$ & Mock crime video & Evading punishment & 0.008 & 1.16 & 1.00 & 0.10 \\
\hline \multirow[t]{2}{*}{ Mangiulli et al. $(2019 b)^{b}$} & $\begin{array}{l}120 \\
\left(\mathrm{~S} n_{l}=40 ; \mathrm{C} n=40\right)\end{array}$ & Mock crime video & Evading responsibility & $<0.0001$ & 0.92 & - & - \\
\hline & $\begin{array}{l}120 \\
\left(\mathrm{~S} n_{2}=40 ; \mathrm{C} n=40\right)\end{array}$ & Mock crime video & Evading responsibility & 0.46 & 0.35 & - & - \\
\hline Mangiulli et al. (2020) & $\begin{array}{l}85 \\
(\mathrm{~S} n=44 ; \mathrm{C} n=41)\end{array}$ & Mock crime video & Evading responsibility & $<0.001$ & 0.96 & - & - \\
\hline
\end{tabular}

n.r. stands for "not reported". Despite reporting here the overall sample sizes used in the experimental studies, it should be noticed that sometimes those included a second control condition (delayed testing-only control group) which was not taken into account in this table. Indeed, the simulated amnesia effect concerns the mnemonic performance between simulating amnesia and truth-telling participants. Specifically, Sn and $\mathrm{Cn}$ refer to the number of participants belonging to the simulating amnesia and truth-telling (i.e., confessors) groups, respectively. Studies marked by $\left({ }^{a}\right)$ employed a different memory test than a cued recall (e.g., recognition, "yes/no"). Studies marked by $\left({ }^{b}\right)$ used two different simulating amnesia groups. Specifically, in Bylin (2002), the second simulating amnesia group (i.e., $\mathrm{Sn}_{2}$ ) was instructed to repeat the simulation throughout two memory sessions; in Bylin and Christianson (2002), the second simulating amnesia group (i.e., $\mathrm{Sn}_{2}$ ) was instructed to do pretend memory loss by distorting information; in Mangiulli et al. (2019a), Mangiulli et al. (2019b)), the second simulating amnesia group (i.e., Sn $\mathrm{n}_{2}$ ) malingered amnesia by practicing and retrieving some information about the mock crime video. Finally, note that in Mangiulli et al. (2019a), the simulating amnesia effect corresponds only to the comparison between simulators and confessors not subjected to the rehearsal manipulation (i.e., no reminder)

amnesia is as follows (see also Otgaar \& Baker, 2018). First, participants are exposed to a crime stimulus (e.g., video of a criminal experience). After that, participants are instructed to either simulate memory loss or confess to the crime (i.e., simulators vs. confessors). Sometimes, a third condition is involved in which participants do not receive any instruction, and who serve as a delayed test-only control condition (i.e., control group; Bylin \& Christianson, 2002; Mangiulli et al., 2018b, 2019a; Sun et al., 2009; Van Oorsouw \& Merckelbach, 2004). After a distractor task, during a first memory phase, participants in the first two conditions (simulators vs. confessors) are asked to comply with their instructions through a memory test (e.g., free and cued recall). Typically, after a 1-week delay, all participants of the two (or three) experimental conditions 
are asked to honestly retrieve what they witnessed during the crime event. In this phase, simulators are asked to give up their role as a simulator and provide an honest account. The standard finding is that, in this latter phase, simulators retrieve fewer crime-related details than confessors (e.g., Christianson \& Bylin, 1999; Van Oorsouw \& Merckelbach, 2004, 2006).

\section{The Cognitive Mechanisms Underling the Simulating Amnesia Effect}

Three major cognitive-related accounts have been put forward to explain people's detrimental memory effects caused by simulating amnesia. Among these, simulators' lack of rehearsal of the crime during the first memory phase (i.e., when participants are instructed to simulate amnesia) appears to be the most parsimonious one (e.g., Christianson \& Bylin, 1999; Van Oorsouw \& Merckelbach, 2004). The reasoning behind this explanation is that in contrast to truth-tellers (i.e., confessors), during the first memory phase, simulators do not elaborately engage in rehearsing the crime. Because rehearsal generally enhances memory for details and events (e.g., Marsh et al., 2005), by complying with the instruction that simulators receive, they have less opportunity to consolidate correct crimerelated information than participants who have to tell the truth. Hence, when coming forward with a truthful memory statement at the final test, simulators correctly recall less information than those who did not simulate memory loss to begin with. This mechanism is supported by findings showing that when a delayed testing-only control group in the experimental design was included, both simulating participants and controls reported a similar amount of information, but still lower than confessors (e.g., Bylin \& Christianson, 2002; Sun, et al., 2009; Van Oorsouw \& Merckelbach, 2004). Thus, according to this account, simulating memory loss would be equivalent as not providing a memory report for the criminal act at all.

However, recent studies are inconsistent with the idea that lack of rehearsal underpins the memory-undermining effect of simulated amnesia (e.g., Mangiulli et al., 2018b, 2019a; McWilliams et al., 2014; Newton \& Hobbs, 2015). In Mangiulli et al. study (Experiment 2, 2019a) when simulators were provided with reminders of the mock crime video, their memory performance was boosted as much as that of confessors, and far better than that exhibited by controls. Furthermore, in the same study, even when not prompted with reminders of the crime, simulating participants reported more correct crime-related details than delayed-testing only controls (see also Mangiulli et al., 2018b; McWilliams et al., 2014; Newton \& Hobbs, 2015). These findings hint to the possibility that simulating amnesia in the first place might paradoxally preserve some traces of the criminal event, at least as compared with not being initially interviewed (Mangiulli et al., 2018b; McWilliams et al., 2014).

A second cognitive mechanism that might underlie the memory-undermining effect of simulated amnesia is related to source monitoring errors (Johnson et al., 1993; Mitchell \& Johnson, 2009), wherein memories for imagined experiences that share several contextual (e.g., spatial and temporal), perceptual (e.g., sound and color), and affective (e.g., emotions) features with real memories might be confused with the original event. Thus, drawing on this idea, Christianson and Bylin (1999) proposed that simulators might incorporate some incorrect details (self-generated during the attempt to simulate memory loss) in their final memory reports, thereby undermining the entire memory for original event. However, other studies (e.g., Van Oorsouw \& Merckelbach, 2004, 2006) did not find support for such a mechanism. Van Oorsouw and Merckelbach (2004) argued that if source monitoring confusion was likely to be an explanation for the simulating amnesia effect, some sort of repeated memory errors between the initial and the final memory phases would have been revealed. Indeed, most studies did not find a link between the number of errors of simulators at the initial memory phase and errors provided during the second one (e.g., Mangiulli et al., 2018a; Van Oorsouw \& Merckelbach, 2004, 2006). Furthermore, Mangiulli et al. (2018a) recently showed that simulators are able of recognizing their own self-generated simulated version of the crime and distinguishing it from the original experience.

Finally, some scholars stipulated that simulators' memory impairments might be caused by retrieval-induced forgetting (RIF; Christianson \& Bylin, 1999; Mangiulli et al., 2019b). RIF refers to forgetting as a consequence of selectively retrieving some information related to the target items (Anderson et al., 1994). Building on this phenomenon, simulators might omit crucial crime-related information (e.g., how the crime occurred) while retrieving only certain elements during the process of simulating amnesia (e.g., peripheral information), thereby exhibiting an overall low memory performance over time. Mangiulli et al. (2019b) examined whether RIF is a driving mechanism for the simulating amnesia effect. That is, by merging both procedures (simulating amnesia for a crime and RIF paradigms), these authors had one group of simulating participants (i.e., simulators retrieval practice) to selectively learn, practice, and retrieve only peripheral information about the crime event, thus omitting crucial crime-related details. Results showed that, even though the practiced phase led these participants to boost their overall memory recall, the percentage of crucial crime-related information was significantly lower than that exhibited by both simulating control participants (i.e., simulators no-retrieval practice) and confessors. Thus, these authors concluded that RIF might partially explain 
simulators' memory detriments if the core of the simulating amnesia effect is represented by memory impairments on crucial crime-related information (Mangiulli et al., 2019b).

\section{The Current Review}

Considering the occurrence of (malingered) crimerelated amnesia claims in court (e.g., Cima et al., 2002; Merckelbach \& Christianson, 2007), it is imperative to provide legal professionals with information about how defendants might remember criminal experiences after having pretended memory loss. Therefore, in the current review, we assembled empirical work on the simulating amnesia effect on memory. Specifically, we focused on experimental studies on the memory-undermining effect of simulated crime-related amnesia. The reason why we focused on this work is because these studies manipulated the simulation of amnesia, thereby being better suited to examine how such a simulation might affect memory as compared with, for instance, field work on offenders claiming to have pretended memory loss. Also, because of some relevant variations in the same studies (e.g., stimuli adopted, procedure, and instructions received), we did not conduct a meta-analysis on the simulating amnesia effect. However, given that memory statements are vital in legal proceedings, we cannot overlook research suggesting that memory failures might take place after the act of simulating amnesia (e.g., Mangiulli et al., 2018b, 2019b; Van Oorsouw \& Merckelbach, 2004) and thus how offenders' final reports might be impacted by this act.

\section{Method}

\section{Sampling Procedure}

A literature search was carried out between June and July 2021 in order to find experimental studies on the memoryundermining effect of simulated amnesia. We included articles from 1998 onwards. The reason for this was because the first study on simulated amnesia for a crime paradigm was published in 1999 (i.e., Christianson \& Bylin, 1999). Using PsycINFO and Google Scholar, we used the following keywords: Feigning amnesia, OR simulating amnesia, OR malingering amnesia AND memory (see PRISMA diagram; Fig. 1). Additionally, we manually retrieved articles from reference lists within the selected papers. Finally, we looked for unpublished studies on the simulating amnesia effect by directly contacting the corresponding authors of the published articles on the simulating amnesia effect. Yet by the time of the submission of the current review, we did not retrieve any additional data or articles.
Three inclusion criteria were adopted to select studies for the current review: The articles had to be peer reviewed, had to be written in English, and had to encompass at least one experimental study on the simulating amnesia effect. Furthermore, variations to the standard procedure (i.e., Christianson \& Bylin, 1999) were included as long as the experimental studies encompassed the following characteristics: (1) participants identified themselves with the offender of a (mock) crime, (2) were instructed to pretend to suffer from memory impairments (i.e., amnesia), (3) were instructed to avoid punishment or responsibility for the same criminal event, (4) and eventually told to come forward with the truth.

A total of 32 articles were found. Of those, only 11 were selected according to the aforementioned characteristics (see Table 2). In the current review, we first focused on three elements that characterized studies on the simulating amnesia effect, namely, (i) crime stimuli (i.e., narrative story, crime video, mock crime), (ii) simulating amnesia instructions (e.g., evade responsibility or avoid punishment), and (iii) memory measures employed (i.e., free recall, cued recall, and other memory tasks). Next, we concentrated on the simulating amnesia effect in terms of (iv) memory outcomes (e.g., low recollection of the event). In this latter respect, the memory-undermining effect of simulated amnesia is solely defined by the comparison between simulating amnesia participants (simulators) and truth-telling participants (confessors). Hence, because we aimed to stress the implications of the offenders' final memory statements after the act of simulated memory loss (see below), our examination regarding the memory outcomes refer only to the difference between simulators and confessors. Finally, we reported on (v) other memory errors sometimes exhibited by simulating participants (i.e., commissions and/or distortions).

\section{Results}

\section{Descriptive Information}

Of the 11 articles selected, $81 \%$ included only one experimental study $\left(n_{\text {articles }}=9 ; n_{\text {experiments }}=9\right.$ ), while the remaining two articles contained two experimental studies each (i.e., Mangiulli et al., 2019a; Sun et al., 2009) (see Table 2). A total of 1061 participants [(under)graduate university students] were involved in the selected studies. The mean age of these participants was 22.94 ( $S D=3.86$; 64\% women). The majority of the experimental studies was conducted in Europe $\left(81 \%, n_{\text {articles }}=10, n_{\text {experiments }}=11\right.$; Italy, Sweden, the Netherlands), while the remaining were run in the USA (i.e., Connecticut). 
Fig. 1 PRISMA 2020 flow diagram reflecting the sampling procedure adopted in the current review

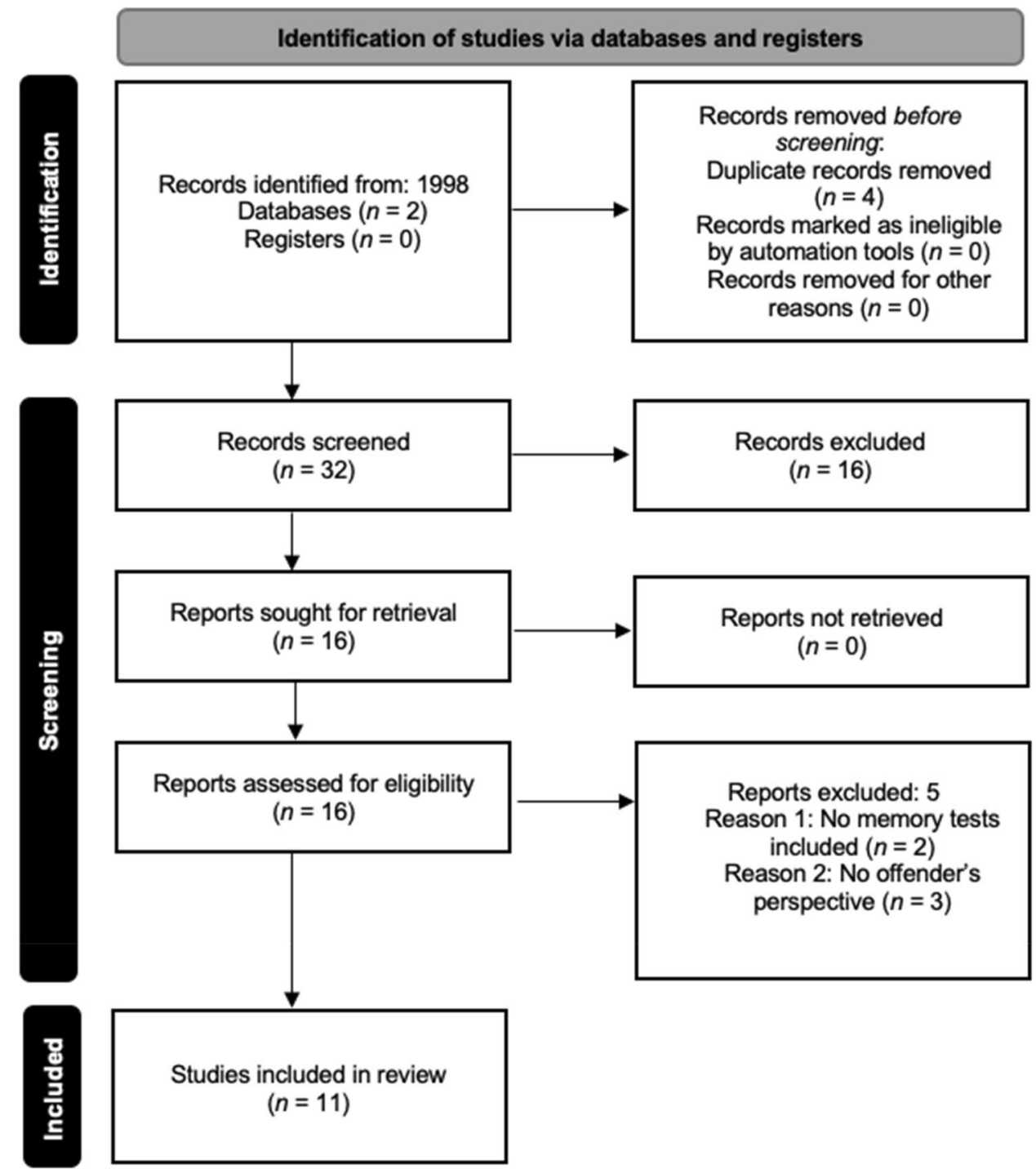

\section{Crime Stimuli}

Since Christianson and Bylin's first article in 1999, 36\% of the work on the simulating amnesia effect has adopted a narrative story as a mock crime stimulus $\left(n_{\text {articles }}=4\right.$, $n_{\text {experiments }}=5$; Bylin, 2002; Bylin \& Christianson, 2002; Christianson \& Bylin, 1999; Sun et al., 2009) (see Table 2). For instance, Christianson and Bylin (1999) and Bylin (2002) used written stimulus material based on real crimes, describing events surrounding the stabbing of a middle-aged man committed by a young man. Alternatively, Bylin and Christianson (2002) used a written narrative consisting of a fictitious story about a traffic crime, in which the perpetrator, intoxicated by alcohol, hit and killed a young woman. Finally, in Sun et al. (2009), participants read a typed story while simultaneously listening to the same spoken narrative. These authors, in an attempt to expose participants to a realistic story, provided them either with a narrative of a perpetrator who, intoxicated by alcohol during a college party, mistakenly killed a puppy by feeding him a chicken bone (Experiment 1), or a perpetrator who, still intoxicated by alcohol, mistakenly gave food containing peanuts to a friend who died from peanut allergy (Experiment 2).

Moreover, the first to use a mock crime video in the simulating amnesia for a crime paradigm were Mangiulli and co-workers ( $36 \%, n_{\text {articles }}=4, n_{\text {experiments }}=5$; Mangiulli et al., 2018a, b, 2019a, b, 2020). In order to avoid the mundane feeling of reading a crime-related story, these authors provided participants with a mock crime video concerning a homicide. That is, in Mangiulli et al. studies (2018b, 2019a; see also Mangiulli et al., 2018a) participants were shown a video (i.e., approximately $2.30 \mathrm{~min}$ ) containing a violent scene portraying a conflict between two armed men. The scene ended with one of the men being strangled by the other. Mangiulli et al. $(2019 b, 2020)$ recently changed the mock crime video by adopting a point of view perspective. 
Because the majority of the people involved in experimental research on the simulating amnesia effect are women, these authors provided participants with a video in which it was not possible to detect the offenders' gender. Accordingly, this could reduce the potential confounding effect caused by the offenders' gender. In this scene (i.e., $3 \mathrm{~min}$ ), a perpetrator after having had dinner at his/her flat goes to the inner city for some drinks. In the restroom of the last club, the offender has a violent fight with another person. The scene ends with the strangling of the victim.

Finally, in the remaining articles $(27 \%, n$ articles $=3, n$ experiments $=3$; Romeo et al., 2018; Van Oorsouw \& Merckelbach, 2004, 2006), participants were asked to perform a mock crime and successively simulate memory loss for it. In their two studies, Van Oorsouw and Merckelbach $(2004,2006)$ instructed their participants to enter a fully equipped bar and hit and knock down a dummy with a pool cue. After doing so, participants were provided with surrounding motives about the crime they just committed. Similarly, Romeo et al. (2018) asked their participants to steal and share the answers to an exam beforehand. Those answers were located into the statistics professor's email account so they were encouraged to steal its password.

\section{Simulating Amnesia Instruction}

Eighty-one percent of the articles on the simulating amnesia effect $\left(n_{\text {articles }}=9, n_{\text {experiments }}=11\right.$ ) offered to participants the same motive to pretend to suffer from memory loss. That is, during the first memory test phase, people were told to evade responsibility or avoid punishment for the (mock) crime (see Table 2). Only first Bylin (2002), and later Van Oorsouw and Merckelbach (2004), slightly changed this instruction in "appearing not guilty" and "minimizing the responsibility" for the event, respectively.

Furthermore, some scholars have also applied some variations to the standard paradigm (i.e., how and when to pretend to suffer from memory loss). For instance, Bylin (2002) tested the effect of repeated simulation on genuine memory for a crime by including a second simulating group (i.e., repeat simulation). These participants were instructed to repeat simulating memory loss, throughout an additional memory session (i.e., the second). Thus, Bylin (2002) used three, rather than the usual two, memory test phases. Bylin and Christianson (2002) investigated possible strategies underpinning the act of simulating amnesia for a crime. In doing so, they asked an additional group of simulating participants to simulate memory loss by distorting important details of the crime so to appear not guilty (i.e., simulation commission). Moreover, in an attempt to investigate possible mnemonic mechanisms underlying the simulating amnesia effect, Mangiulli et al. (2019b) pitted a second simulating amnesia group against the standard one. That is, while one group of simulators was told to simply malinger amnesia, a second group was asked to simulate memory loss by selectively retrieving, and omitting, specific actual information about the crime in an attempt to be consistent with their amnesic claims.

\section{Memory Measures}

In general, participants were usually tested individually in a quiet test room (but see Bylin, 2002, in which 5-10 people were tested simultaneously). It is important to stress that, in the studies, memory measures were kept consistent throughout the experiments, meaning that the same tests were used across the different sessions. The majority of the articles on the simulating amnesia effect used at least two memory measures $\left(63 \%, n_{\text {articles }}=7, n_{\text {experiments }}=9\right)$ (see Table 2$)$. The most common memory measure used was the free recall $\left(91 \%, n_{\text {articles }}=10, n_{\text {experiments }}=12\right)$, wherein participants were invited to write down their memory statements, irrespective of the instruction received (simulating vs. confessing). Usually, participants were instructed to report the course of the event in a "I/me" style, because they were supposed to identify themselves with the perpetrator of the crime. While only in three articles participants were invited to write their reports within $20 \mathrm{~min}$ (Bylin, 2002; Christianson \& Bylin, 1999; Van Oorsouw \& Merckelbach, 2004), in the remaining studies they were given as much time as needed to do so. The average time delay between the initial and final free recall test was 6.6 days $(S D=3.3)$.

Furthermore, the second most frequent memory measure employed in the articles was cued recall $\left(54 \%, n_{\text {articles }}=6\right.$, $n_{\text {experiments }}=8$ ), namely, answering to a pre-set of questions either in oral or written form (e.g., "Where did the murder take place?"; Mangiulli et al., 2018b). On average, participants were asked 21.3 (range: 11-37; $S D=9.4$ ) open-ended questions about the crime event. The average time delay between the initial and final cued recall test was 7 days $(S D=0.1)$.

On a small note, in Bylin (2002) a recognition task was employed, rather than a cued recall, that comprised 41 multiple-choice questions. On such a test, truth-telling participants (confessors) recognized more correct information than simulating participants $(p<0.05$; but no statistically significant difference was observed between the former and those simulators who repeated simulation). Also, in Bylin and Christianson (2002), an additional recognition task was used alongside the typical free and cued recall, wherein participants provided responses to 26 multiple-choice questions concerning details from the narrative story. However, no statistically significant differences were found between groups (simulators vs. confessors).

Finally, in a recent study by Romeo et al. (2018) neither of the aforementioned measures was used. Instead, those authors applied a "yes/no" source monitoring test. That 
is, the source monitoring test concerned questions about true (i.e., actual details encoded during the mock crime) and false information (i.e., details not presented during the mock crime). The source monitoring test was administered both for the interview (i.e., first memory session), and for the mock crime event. Results showed that simulating participants' memory reports were undermined only for true and false details concerning questions asked during the first memory session ( $p=0.04$, and $p<0.01$, respectively). However, the authors did not find the memory-undermining effect of simulated amnesia for the mock criminal event (see Table 2).

\section{The Simulating Amnesia Effect}

As stated above, the memory-undermining effect of simulated amnesia is expressed by the comparison between simulating amnesia participants and truth-tellers (confessors) on the number of reported correct details of the crime event at the final memory test. That is, simulators typically report fewer correct details than confessors. Here, we focused on the most used memory tests, namely, free and cued recalls, because there were very few studies on other memory measures (e.g., recognition task) that would allow us to provide any aggregated data. Of course, these data should be interpreted with caution considering the different variations among studies (e.g., different instructions, different stimuli).

Participants' memory performance on the free recall is usually reported in absolute numbers (e.g., Bylin, 2002) or proportions (range: 0-1; Mangiulli et al., 2018b; Van Oorsouw \& Merckelbach, 2004). The simulating amnesia effect has been found in all of the selected articles that included a free recall ( $\left.n_{\text {articles }}=10\right)$ and in $92 \%$ of the experiments conducted ( $\left.n_{\text {experiments }}=11\right)$, with a Cohen's $d$ effect size ranging from medium to large (range: 0.6-1.3). Usually free recall was scored by giving one point for each correct piece of information reported into participants' statements. Across all the experiments, during the free recall, on average participants could recall a maximum of 64.5 details $^{2}(S D=38.2)$ pertaining to the crime event. When asked to come forward with the truth during the second memory test, simulators reported $33.7 \%$ of the total information $(M=21.7, S D=14.3)$, while, by contrast, confessors recalled $44.1 \%$ of the same information $(M=28.4, S D=19)$. In other words, on average simulating participants reported $10.4 \%$ less correct information than confessors when truthfully recalling the event, which in turn corresponds to $6.7(S D=4.7)$ details related to

\footnotetext{
2 The overall maximum number of details that participants could recall during the free recall test was based on the average of the predefined number of details for each study.
}

the crime event. Welch's independent-sample t-test (onetailed) was calculated ${ }^{3}$ on that difference, $t(21.73)=-1.72$, $p=0.05$ with a $d=0.70$, implying that about two thirds of the confessor group will be above the mean of the simulation group (Magnusson, 2021).

Similarly, also cued recall scores were reported either in absolute numbers (e.g., Bylin, 2002) or proportion (range: 0-1; Mangiulli et al., 2018b; Van Oorsouw \& Merckelbach, 2004). The simulating amnesia effect has been found in $66 \%$ of the selected articles that used a cued recall $\left(n_{\text {articles }}=4\right)$ and in $62 \%$ of the experiments conducted $\left(n_{\text {experiments }}=5\right)$, with a Cohen's $d$ effect size ranging from medium to large ${ }^{2}$ (range: 0.7-1.5). As for the free recall, also the cued recall was typically scored by assigning one point for each correct piece of information reported by participants. Among the selected experiments, during the cued recall, participants could report a maximum of 38.8 details $(S D=38.2)$ pertaining to the crime stimulus. During the second memory test (i.e., genuine recollection), simulators displayed $64.7 \%$ of the total information $(M=25.1, S D=3.1)$, while confessors reported $72.6 \%(M=28.2, S D=3.8)$ of the same information. Hence, when honestly accounting for the crime event during a cued recall, simulators recall $7.9 \%$ less information than confessors, which corresponds to 2.9 details $(S D=0.7)$. A Welch's independent-sample t-test (one-tailed) was computed ${ }^{2}$ on that difference revealing $t(9.99)=-1.28$, $p=0.114, d=0.74$.

\section{Other Memory Errors}

In addition to correct recall rates, other dependent variables were often taken in consideration in the articles on the simulating amnesia effect, namely, the number of omission (i.e., withholding information) and commissions (i.e., newly fabricating information) and/or distortions (i.e., altering existing details) reported during the final memory test. Only $50 \%$ of the selected articles, which included at least a free recall as a memory measure, inspected omission errors $\left(n_{\text {articles }}=5, n_{\text {experiments }}=5\right)$. Yet it should be noticed that this memory measure is not informative because this outcome virtually mirrors simulating participants' weak performance with respect to the correctness rate. That is, simulators made more omission errors because they recalled less correct information about the crime event as compared with truthtelling participants (confessors) (e.g., Christianson \& Bylin, 1999; Van Oorsouw \& Merckelbach, 2004).

Much more interesting is the mixed pattern of results on commissions and/or distortions exhibited by simulating

\footnotetext{
${ }^{3}$ Welch's independent-sample t-tests (both for free and cued recall) were calculated, for each study, based on simulators' and confessors' means divided by the maximum amount of information.
} 
participants on the free recall memory task during the final memory test. These errors were usually displayed in absolute numbers (but see Sun et al., 2009). Sometimes, both distorted and self-generated details were collapsed under the label commission errors (e.g., Mangiulli et al., 2018b; Van Oorsouw \& Merckelbach, 2004, 2006), incorrect recall (e.g., Sun et al., 2009), or simply errors (e.g., Mangiulli et al., 2019a, b). Commissions and/or distortions were examined in all the selected articles that employed the free recall as a memory measure (articles $=10, n_{\text {experiments }}=12$ ). However, despite overall numerically reporting more commissions and/or distortions (e.g., Christianson \& Bylin, 1999; Sun et al., 2009), simulators statistically significantly differed $^{4}$ from confessors during the final test only in $20 \%$ of these articles (Mangiulli et al., 2019b; Van Oorsouw \& Merckelbach, 2006), with a medium Cohen's $d$ effect size (range: 0.5-0.7).

By contrast, almost all the studies investigated participants' commission and/or distortion rates reported during the cued recall $\left(83 \%, n_{\text {articles }}=5, n_{\text {experiments }}=6\right)$. However, except for Christianson and Bylin (1999), no studies have found that simulators statistically significantly endorsed more errors than confessors on a cued recall task at the final memory session.

\section{Discussion}

In the current manuscript, we reviewed experimental studies on the memory undermining effect of simulated amnesia. Taken together, research on this effect showed that pretending to suffer from memory loss for a mock crime leads to memory impairments. These memory impairments are expressed mostly in terms of omission errors (i.e., overall less correct information recalled) and, in a very few occasions, commissions and/or distortions over time (i.e., reporting details not presented during the crime stimuli) (see also Battista et al., 2020, 2021; Otgaar \& Baker, 2018; Van Oorsouw \& Giesbrecht, 2008). Such a detrimental memory effect has been demonstrated in a nontrivial number of experimental studies and shown by using different stimuli (e.g., narrative stories, mock crimes, and videos) and various memory measures (e.g., free and cued recall) (Christianson \& Bylin, 1999; Mangiulli et al., 2018b, 2019a, b; Van Oorsouw \& Merckelbach, 2004). Yet in this latter respect, the memory-undermining effect of simulated amnesia largely emerges more during free than cued recall.

\footnotetext{
${ }^{4}$ We did not compute any statistical analyses on the commissions and/or distortion (i.e., Welch's independent-sample t-test) becausein contrast to correct rates-participants' commission and/or distortion rates depend on the number of errors that each person reports individually on the memory tests (e.g., free and cued recall).
}

Despite of being a robust memory phenomenon, it is important to mention some limitations of the current review and, needless to say, of the experimental studies pertaining to simulating crime-related amnesia. To begin with, our review collected only published experiments on the simulating amnesia effect. It could likely be that our set of articles may have been biased by selection effects. For instance, some scholars might have not replicated the memoryundermining effect of simulated amnesia, but their studies were not published and we failed to retrieve them. Moreover, by looking at the evidence provided by the experimental studies on the simulating amnesia effect, one might wonder to what extent it is possible to generalize these results to the real-life world. This issue arises from at least three limitations of the studies examining the simulating amnesia effect. First, recollections of a mock crime in laboratory studies are typically administered after 1-week delay. In real-life situations, however, the delay between the criminal act and the police interrogations may be much longer. Hence, the passage of time may have an additional impact on suspects' memory statements (Murre \& Dros, 2015). Second, the findings reported in the current review are based on studies that involve mostly female university students, which differ in various means from people who commit severe crimes. Also, often offenders' education, socio-economic environment, previous experience with criminality, expectations, and/or experience with memory loss were not taken into account in laboratory studies. Hence, researchers may have disregarded the different ways in which these features may affect actual offenders' recollection of the crime event. Third, actual crimes are likely more emotionally arousing, traumatic, and salient than the mock crime stimuli adopted in this line of research. We cannot neglect that especially this aspect, irrespective of malingering amnesia for a crime or not, plays an essential role in how people remember (or forget) criminal experiences (Evans, 2006).

So, why is experimental work on the effect of crimerelated amnesia important? To the degree that some of the mnemonic mechanisms can overlap regardless of the type of populations (e.g., university students vs. real offender), this line of research points towards a growing line of evidence showing that malingering memory loss may lead to memory impairments pertaining to an offense. This finding cannot be discounted given that it is well-known that a substantial percentage of offenders malinger amnesia in an attempt to interfere with the legal system (Bourget \& Whitehurst, 2007; Cima et al., 2002; Porter et al., 2001). Thus, a relevant question here is what is meant to be relevant as a "forgotten" crime-related information, and subsequently, whether the overall weak simulators' memory statements could be of importance for the legal system. Indeed, one could argue that not all the information has the same relevance for police investigations and/or the trial proceedings. For instance, 
from a legal point of view, there is a substantial difference between forgetting how and why the crime has occurred and the color of the vehicle with which the offender reached the crime scene. In our review, we found that, during the free recall, on average simulating participants recalled approximately $10 \%$ less correct information than people who immediately confess to the crime, which corresponds to almost 7 crime details. Still, Christianson and Bylin (1999) already showed that that simulators' lower recall mostly referred to crime-relevant information (e.g., physical act). Van Oorsouw and Merckelbach (2004), moreover, controlled for the possibility that less crucial details (e.g., played pool) could have had similar recall score as more crucial ones (e.g., victim's clothing). These authors found that non-relevant details did not have a considerable weight on the final memory tests, meaning that simulators' memory impairments mostly concerned crucial crime-related information. More precisely, Mangiulli et al. (2019b) showed that when simulators were instructed to selectively retrieve non-relevant crime-related details while omitting crucial ones, these participants' final memory reports lacked relevant details pertaining to the crime as compared with controls.

Undoubtedly, the issue pertaining to whether forgetting crime-related information in laboratory setting has a meaningful practical relevance is a timely matter. The basic reasoning here is that experimental studies, supported by solid theoretical background, should produce effects of relevance for the (legal) field. Throughout our review, we emphasized that the act of pretending memory loss for a crime can detrimentally influence offenders' memory reports and this is informative to legal professionals. In other words, to some extent, remembering or forgetting even one crucial-crimerelated detail might lead to some severe consequences for the legal realm.

\section{Legal Implications Following Simulated Crime-Related Amnesia Claims}

If defendants initially claim memory loss for their deeds and later on come forward with the truth, they might encounter problems in correctly retrieving parts of the crime event. This issue might occur, for instance, in circumstances in which defendants are determined to cooperate with the justice departments, such as in plea bargaining cases. In this scenario, a partially correct memory statement for the crime might be of a problem both during the police investigations and the trial proceedings. To begin with, there could be a potential risk of undisclosed information in high-stake cases, for instance, when perpetrators and victims are the sole witnesses to a crime. If the perpetrator's memory statement was impaired by the act of pretending memory loss, some vital details regarding a crime would remain undisclosed.
Second, defendants' memory accounts are also essential for the judges to determine the right sentence. In some circumstances, the defendant's confession is helpful for judges to determine whether the crime has been premeditated or not. A premeditated felony has much more severe consequences than, for instance, voluntary manslaughter, especially in specific jurisdictions (e.g., the USA). Roesch and Golding (1986) exemplified the potential of this issue in a crime-related amnesia case. An offender who reported memory loss for sexual assault and capital murder was given the capital sentence. However, some (forgotten) details concerning sexual assault came to light, leading the judge to drop that charge. Indeed, sexual assault did not occur. Eventually, the man pled guilty to second degree murder and avoided the death penalty. Even though quite unique, this case emphasizes the possible legal-related issues concerning memory impairments due to malingering amnesia for a crime.

Relatedly, and third, research has shown that people tend to believe that a testimony is more credible when it is more detailed (Pennington \& Hastie, 1988; Rogers \& Bender, 2018). Thus, if defendants truthfully come forward with an incomplete, less detailed, version of the crime, their memory statements might be disregarded as credible. Hence, offenders should be aware that pretending to suffer from memory loss may lead to forgetting some details of the crime event. This paradoxical issue, as just depicted in the case above, would not be in the best interest of suspects/defendants.

Fourth, if defendants have memory impairments due to the act of pretending memory loss for a crime, this might jeopardize the ability of that person to consult with his/her attorney and hence the accused's right to a fair trial. Note that these two arguments, which raise both doctrinal and practical issues (Tysse, 2005; Tysse \& Hafemeister, 2006), have been already put forward even in situations in which defendants do not come forward with a confession and maintain their amnestic profile (see Bourget \& Whitehurst, 2007; Porter et al., 2001). Although crime-related amnesia in itself does not represent a bar for people's ability to stand trial in the majority of the jurisdictions, in some countries such as the USA, some argue that temporary or permanent memory loss may put the preparation of the defendant's defense at risk (see Wilson v. U.S., 1968), advocating that the accused should be found incompetent to stand (Koson \& Robey, 1973). Consequently, some have additionally reasoned whether that could represent a violation to the defendants' due process (Hermann, 1986). Simply put, if defendants cannot (1) notify their attorney about the circumstances of the alleged criminal event because they do not remember (part of) their crimes, (2) nor recognize misleading and/or false accusations surrounding their own cases, their right to a fair trial might be violated and, needless to say, denied.

An ultimate further point that deserves comment is the heated dichotomy between dissociative and malingered 
amnesia claims in the criminal context. Inserted in a criminal context, dissociative amnesia is the result of a blocking of unwanted memories (i.e., for criminal offenses) from the offenders' consciousness, thereby protecting them as a form of coping or defense mechanism (Parkin, 1999; Parwatikar et al., 1985). Yet evaluating such a claim is a difficult matter for both clinicians and forensic experts (Jelicic, 2018; Kopelman, 1995; Merckelbach \& Christianson, 2007). As Porter et al. (2001) noticed, the consequences of misjudging the veracity of crime-related amnesia claims can be severe. Judges might consider mitigating the sentence, and perhaps send defendants to forensic psychiatric hospitals, rather than prisons, if they take malingered amnesic claims as evidence for dissociative memory loss. Yet the contrary might also be true. If a genuine claim of dissociative amnesia is erroneously viewed as malingered, people can be held accountable for a criminal action. However, dissociative amnesia per se represents a very controversial issue (Mangiulli et al., 2021a; McNally, 2003, 2007), and its construct is often questioned especially when exerted in court. Recent data show that contentious concepts such as dissociative amnesia are present and used in a substantial number of legal proceedings, encouraging non scientifically based evidence in support of crime-related (dissociative) amnesia claims (see Otgaar et al., 2019). Moreover, some authors promoting dissociative amnesia case studies seem to not take into account the possibility that, in these circumstances, malingering could be a valid alternative explanation for dissociative amnesia (see for a critical review on dissociative amnesia case studies: Mangiulli et al., 2021a). For instance, Brand et al. (2009) reported on a patient ("H.H.", already charged for two sexual offenses) who claimed memory loss for sexual duress. According to these authors, the notification of the newest accusation was the critical incident prior to the patient's amnesic onset. Interestingly, however, Brand et al. (2009) did not examine whether their patient was malingering memory loss nor conduct any proper forensic examination to examine this possibility.

Having said this, we wonder how many of the offenders' claims of memory loss perhaps might be due to the act of having previously simulated amnesia. That is, if we consider that malingered crime-related amnesia claims are nontrivial in the courtroom, and some offenders eventually do come forward with a confession, it would not be so farfetched to venture that, at least in part, such memory impairments might be explained by the act of having initially malingered amnesia. In this respect, thus, the cognitiverelated mechanisms underlying the detrimental consequences of simulating amnesia (e.g., lack of rehearsal, source monitoring, retrieval-induced forgetting) might perhaps represent valid alternatives to an interpretation in favor of crime-related dissociative amnesia. Of course, we do not fully know how many real offenders actually suffer from memory impairments following a malingered crimerelated amnesia claim. However, the historic case of Rudolf Hess (Picknett et al., 2001) illustrates how such a situation is far from being science-fiction. Hess claimed amnesia for his entire Third Reich period during the beginning of the Nuremberg trial in 1945. Some prominent psychiatrists that evaluated Hess concluded that his memory loss was genuine. However, when Hess found out that because of his amnesia claim he could not respond to the allegations made against him, he eventually stated during one of the trial sessions that he malingered his memory loss. Furthermore, there is some evidence coming from (self-report) surveys suggesting that this phenomenon could indeed take place also in real life situations. For instance, Riesthuis et al. (2021) noticed that $64.1 \%(n=98 / 153)$ of people, who admitted to have malingered memory loss at least once in their everyday life, eventually struggled in retrieving the original event. Similarly, Mangiulli et al. (2021b) found that among people who had claimed to pretend to suffer from memory loss, more than half $(54.1 \%, n=93 / 172)$ eventually reported to have had difficulties in recalling the memory for which they malingered amnesia.

\section{Future Directions in Research and Practice}

Having established the robustness of the memory-undermining effect of simulated amnesia and its legal consequences, future investigations should concentrate to bridge the gap between research and practice. First of all, in real-life situations, memories for crimes often have a strong emotional component. On the one hand, some scholars argue that memories for a crime are unlikely to be forgotten because of their emotional valence (Christianson \& Engelberg, 2006; McGaugh, 2006). On the other hand, other researchers suggest that people may voluntarily be motivated to forget unwanted and unpleasant memories of these same experiences and thus manifesting some sort of memory impairments (Anderson \& Green, 2001; Anderson \& Hanslmayr, 2014). Conceivably, taking into account all the ethical precautions, experimental studies on the memory-undermining effect of simulated amnesia might certainly benefit in terms of ecological validity if they tried to resemble as much as possible a criminal situation. Because the majority of the studies in this field used similar stimuli (written narrative or video, e.g., Bylin, 2002; Mangiulli et al., 2018b, 2019a; Sun et al., 2009), it would be interesting for future experimental studies to compare different crime materials. Indeed, researchers in this field may begin to use more often ecologically valid set-ups (e.g., (e.g., using traumatic virtual reality experiences; see Romeo et al., 2019). Additionally, in order to further consolidate results coming from laboratory studies, it would be wise to employ real offenders into the simulating crime-related amnesia paradigm. Exposing 
this specific population to the standard procedure as illustrated in this review could perhaps bear results similar to that observed among university students.

Moreover, the number of defendants who exhibit memory impairments after having malingered memory loss for a crime is still unknown. Despite crime-related amnesia being common (e.g., Cima et al., 2002; Jelicic, 2018), to our knowledge no research has examined whether violent perpetrators keep showing memory deficits related to their offenses even if they eventually admitted to have malingered their memory loss. It is necessary, thus, to conduct archive and/or new field studies to establish the prevalence of this phenomenon in legal settings.

Finally, we observed that the simulated amnesia effect is larger when simulators are asked to freely recall the event than when they are prompted with cued questions or reminders of the event (e.g., Mangiulli et al., 2018b, 2019b). This finding could be of importance for practical situations. Specifically, research provides some well-established cognitivebased interview tools (e.g., Cognitive Interview; Fisher \& Geiselman, 1992; Fisher \& Perez, 2007) which might facilitate retrieval of criminal actions during informationgathering investigations (Meissner et al., 2012; Memon et al., 2010). More specifically, if we assumed that memories for a crime are solidly stored as a result of its emotional component (Christianson \& Engelberg, 2006; McGaugh, 2006), offenders' memory impairments would be due to a retrieval rather than an encoding deficit. Hence, finding a way to retrieve unreported crucial crime-related information from offenders who initially malingered amnesia might represent a new appealing research avenue.

\section{Concluding Remarks}

In the current review, we highlighted the empirical features of the experimental work on the memory-undermining effect of simulated crime-related amnesia. We stressed that pretending to suffer from memory loss for a crime might paradoxically even lead to real memory problems when simulators come forward with a confession. Of course, in the light of the obvious difference between experimental work and real-life situations, caution should be exerted when generalizing these effects to actual crime-related amnesia cases. In this respect, new laboratory and field investigations are needed to ascertain to what extent offenders' memory deficits might actually be due to the act of simulating memory loss. Still, even though it might be unlikely that actual offenders completely erase the entire criminal event from memory in the absence of any organic dysfunctions, we showed that some form of forgetting related to crucial crime-related details might take place. We conclude, therefore, that the issue concerning these memory impairments represents an important factor that legal professionals should consider while examining defendants' memory statements in crime-related amnesia cases.

\section{Funding Sources}

The current review has been supported by a $\mathrm{C} 1$ grant (Application number: C14/19/013) from the KU Leuven (Belgium) and a FWO Senior Research Project grant (Application number: G0D3621N; Research Foundation - Flanders, Belgium) awarded to Henry Otgaar.

Open Access This article is licensed under a Creative Commons Attribution 4.0 International License, which permits use, sharing, adaptation, distribution and reproduction in any medium or format, as long as you give appropriate credit to the original author(s) and the source, provide a link to the Creative Commons licence, and indicate if changes were made. The images or other third party material in this article are included in the article's Creative Commons licence, unless indicated otherwise in a credit line to the material. If material is not included in the article's Creative Commons licence and your intended use is not permitted by statutory regulation or exceeds the permitted use, you will need to obtain permission directly from the copyright holder. To view a copy of this licence, visit http://creativecommons.org/licenses/by/4.0/.

\section{References}

Anderson, M. C., Bjork, R. A., \& Bjork, E. L. (1994). Remembering can cause forgetting: Retrieval dynamics in long-term memory. Journal of Experimental Psychology: Learning, Memory, and Cognition, 20, 1063-1087. https://doi.org/10.1037/0278-7393.20.5.1063

Anderson, M. C., \& Green, C. (2001). Suppressing unwanted memories by executive control. Nature, 410, 366-369. https://doi.org/10. $1038 / 35066572$

Anderson, M. C., \& Hanslmayr, S. (2014). Neural mechanisms of motivated forgetting. Trends in Cognitive Sciences, 18, 279-292. https://doi.org/10.1016/j.tics.2014.03.002

Battista, F., Mangiulli, I., Herter, J., Curci, A., \& Otgaar, H. (2020). The effects of repeated denials and fabrication on memory. Journal of Cognitive Psychology, 34, 369-381. https://doi.org/10. 1080/20445911.2020.1767626

Battista, F., Mangiulli, I., Riesthuis, P., Curci, A., \& Otgaar, H. (2021). Do liars really remember what they lied upon? The impact of fabrication on memory. Memory, 29, 1076-1090. https://doi.org/ 10.1080/09658211.2021.1960380

Bell, B. E., \& Loftus, E. F. (1988). Degree of detail of eyewitness testimony and mock juror judgments. Journal of Applied Cognitive Psychology, 18, 1171-1192. https://doi.org/10.1111/j.1559-1816. 1988.tb01200.x

Bourget, D., \& Whitehurst, L. (2007). Amnesia and crime. Journal of the American Academy of Psychiatry and the Law, 35, 469-480.

Bradford, J. M. W., \& Smith, S. M. (1979). Amnesia and homicide: The Padola case and a study of thirty cases. Journal of the American Academy of Psychiatry and the Law Online, 7, 219-231.

Brand, M., Eggers, C., Reinhold, N., Fujiwara, E., Kessler, J., Heiss, W. D., \& Markowitsch, H. J. (2009). Functional brain imaging in 14 patients with dissociative amnesia reveals right inferolateral 
prefrontal hypometabolism. Psychiatry Research: Neuroimaging, 174, 32-39. https://doi.org/10.1016/j.pscychresns.2009.03.008

Bylin, S. (2002). How does repeated simulation of memory impairment affect genuine memory performance? Psychology, Crime and Law, 8, 265-288. https://doi.org/10.1080/10683160208401819

Bylin, S., \& Christianson, S. A.. (2002). Characteristics of malingered amnesia: Consequences of withholding vs. distorting information on later memory of a crime event. Legal and Criminological Psychology, 7, 45-61. https://doi.org/10.1348/135532502168379

Centor, A. (1982). Criminals and amnesia: Comment on Bower. American Psychologist, 37, 240.

Christianson, S. A., \& Bylin, S. (1999). Does simulating amnesia mediate genuine forgetting for a crime event? Applied Cognitive Psychology, 13, 495-511. https://doi.org/10.1002/(SICI) 1099-0720(199912)13:6\%3c495::AID-ACP615\%3e3.0.CO;2-0

Christianson, S. A., \& Engelberg, E. (2006). Remembering emotional events: The relevance of memory for associated emotions. In B. Uttl, N. Ohta, \& A. L. Siegenthaler (Eds.), Memory and emotion: Interdisciplinary perspectives (p. 59-82). Blackwell Publishing. https://doi.org/10.1002/9780470756232.ch4

Cima, M., Merckelbach, H., Hollnack, S., \& Knauer, E. (2003). Characteristics of psychiatric prison inmates who claim amnesia. Personality and Individual Differences, 35, 373-380.

Cima, M., Merckelbach, H., Nijman, H., Knauer, E., \& Hollnack, S. (2002). I can't remember your honor: Offenders who claim amnesia. German Journal of Psychiatry, 5, 24-34.

Cima, M., Nijman, H., Merckelbach, H., Kremer, K., \& Hollnack, S. (2004). Claims of crime related amnesia in forensic patients. International Journal of Law and Psychiatry, 27, 215-221. https://doi.org/10.1016/j.ijlp.2004.03.007

Cima, M., \& Van Oorsouw, K. (2013). The relationship between psychopathy and crime-related amnesia. International Journal of Law and Psychiatry, 36, 23-29. https://doi.org/10.1016/j.ijlp.2012.11.004

Engelkamp, J., Zimmer, H. D., Mohr, G., \& Sellen, O. (1994). Memory of self-performed tasks: Self-performing during recognition. Memory \& Cognition, 22, 34-39. https://doi.org/10.3758/ BF03202759

Evans, C. (2006). What violent offenders remember of their crime: Empirical explorations. Australian \& New Zealand Journal of Psychiatry, 40, 508-518. https://doi.org/10.1080/j.1440-1614. 2006.01833.x

Evans, C., Mezey, G., \& Ehlers, A. (2009). Amnesia for violent crime among young offenders. The Journal of Forensic Psychiatry \& Psychology, 20, 85-106. https://doi.org/10.1080/ 14789940802234471

Fisher, R. P., \& Geiselman, R. E. (1992). Memory enhancing techniques for investigative interviewing: The cognitive interview. Thomas Publisher.

Fisher, R. P., \& Perez, V. (2007). Memory-enhancing techniques for interviewing crime suspects. In S. A. Christianson (Ed.), Offenders' memories of violent crimes (pp. 329-354). Wiley. https://doi.org/10.1002/9780470713082.ch14

Goodwin, D. W. (1995). Alcohol amnesia. Addiction, 90, 315-317. https://doi.org/10.1080/09652149542292

Gudjonsson, G. H. (2003). The psychology of interrogations and confessions: A handbook. John Wiley \& Sons. https://doi.org/ $10.1002 / 9780470713297$

Gudjonsson, G. H. (2006). Sex offenders and confessions: How to overcome their resistance during questioning. Journal of Clinical Forensic Medicine, 13, 203-207. https://doi.org/10.1016/j. jcfm.2006.02.003

Gudjonsson, G. H., Hannesdottir, K., \& Petursson, H. (1999). The relationship between amnesia and crime: The role of personality. Personality and Individual Differences, 26, 505-510. https:// doi.org/10.1016/S0191-8869(98)00165-2
Gudjonsson, G. H., Pétursson, H., Skúlason, S., \& Siguroardottir, H. (1989). Psychiatric evidence: A study of psychological issues. Acta Psychiatrica Scandinavica, 80, 165-169. https://doi.org/ 10.1111/j.1600-0447.1989.tb01321.x

Guttmacher, M. S. (1955). Psychiatry and the law. Grune and Stratton.

Hermann, D. H. (1986). Criminal defenses and pleas in mitigation based on amnesia. Behavioral Sciences \& the Law, 4, 5-26. https://doi.org/10.1002/bsl.2370040102

Hopwood, J. S., \& Snell, H. K. (1933). Amnesia in relation to crime. Journal of Mental Science, 79, 27-41. https://doi.org/10.1192/ bjp.79.324.27

Jelicic, M. (2018). Testing claims of crime-related amnesia. Frontiers in Psychiatry, 9, 617. https://doi.org/10.3389/fpsyt.2018.00617

Jelicic, M., \& Merckelbach, H. (2007). Evaluating the authenticity of crime-related amnesia. In S. A. Christianson (Ed.), Offenders' memories of violent crimes (pp. 215-233). Wiley. https://doi.org/ 10.1002/9780470713082.ch9

Johnson, M. K., Hashtroudi, S., \& Lindsay, D. S. (1993). Source monitoring. Psychological Bulletin, 114, 3-28. https://doi.org/10.1037/ 0033-2909.114.1.3

Kensinger, E. A., \& Ford, J. H. (2020). Retrieval of emotional events from memory. Annual Review of Psychology, 71, 251-272. https:// doi.org/10.1146/annurev-psych-010419-051123

Kopelman, M. D. (1995). The assessment of psychogenic amnesia. In A. D. Baddeley, B. A. Wilson, \& F. N. Watts (Eds.), Handbook of memory disorders (pp. 427-448). John Wiley.

Koson, D., \& Robey, A. (1973). Amnesia and competency to stand trial. American Journal of Psychiatry, 130, 588-592.

Leitch, A. (1948). Notes on amnesia in crime for the general practitioner. The Medical Press, 219, 459-463.

Lynch, B. E., \& Bradford, J. M. W. (1980). Amnesia: Its detection by psychophysiological measures. Journal of the American Academy of Psychiatry and the Law Online, 8, 288-297.

Magnusson, K. (2021). Interpreting Cohen's d effect size: An interactive visualization (Version 2.5.0) [Web App]. Retrieved from https://rpsychologist.com/cohend/

Mangiulli, I., Jelicic, M., Patihis, L., \& Otgaar, H. (2021a). Believing in dissociative amnesia relates to claiming it: A survey of people's experiences and beliefs about dissociative amnesia. Memory, 29, 1362-1374. https://doi.org/10.1080/09658211.2021.1987475

Mangiulli, I., Lanciano, T., Jelicic, M., Van Oorsouw, K., Battista, F., \& Curci, A. (2018a). Can implicit measures detect source information in crime-related amnesia? Memory, 26, 1019-1029. https://doi. org/10.1080/09658211.2018.1441421

Mangiulli, I., Lanciano, T., Van Oorsouw, K., Jelicic, M., \& Curci, A. (2019a). Do reminders of the crime reverse the memory-undermining effect of simulating amnesia? Memory \& Cognition, 47, 1375-1385. https://doi.org/10.3758/s13421-019-00939-z

Mangiulli, I., Otgaar, H., Curci, A., \& Jelicic, M. (2020). An experimental investigation of the misinformation effect in crime-related amnesia. Applied Cognitive Psychology, 34, 1092-1100. https:// doi.org/10.1002/acp.3697

Mangiulli, I., Otgaar, H., Jelicic, M., \& Merckelbach, H. (2021b). A critical review of case studies on dissociative amnesia. Clinical Psychological Science, 1-21. https://doi.org/10.1177/21677026211018194

Mangiulli, I., Van Oorsouw, K., Curci, A., \& Jelicic, M. (2019b). Retrieval-induced forgetting in the feigning amnesia for a crime paradigm. Frontiers in Psychology, 10, 928. https://doi.org/10. 3389/fpsyg.2019.00928

Mangiulli, I., Van Oorsouw, K., Curci, A., Merckelbach, H., \& Jelicic, M. (2018b). Feigning amnesia moderately impairs memory for a mock crime video. Frontiers in Psychology, 9, 625. https://doi. org/10.3389/fpsyg.2018.00625

Marsh, E. J., Tversky, B., \& Hutson, M. (2005). How eyewitnesses talk about events: Implications for memory. Applied Cognitive Psychology, 19, 531-544. https://doi.org/10.1002/acp.1095 
McGaugh, J. L. (2006). Memory and emotions: Making lasting memories. Columbia University Press.

McNally, R. J. (2007). Dispelling confusion about traumatic dissociative amnesia. Mayo Clinic Proceedings, 82, 1083-1090. https:// doi.org/10.4065/82.9.1083

McNally, R. J. (2003). Remembering trauma. Harvard University Press. https://doi.org/10.1038/nm1203-1448

McWilliams, K., Goodman, G. S., Lyons, K. E., Newton, J., \& Avila-Mora, E. (2014). Memory for child sexual abuse information: Simulated memory error and individual differences. Memory \& Cognition, 42, 151-163. https://doi.org/10.3758/s13421-013-0345-2

Meissner, C., Redlich, A., Bhatt, S., \& Brandon, S. (2012). Interview and interrogation methods and their effects on investigative outcomes. Campbell Systematic Reviews, 8, 1-49.

Memon, A., Meissner, C. A., \& Fraser, J. (2010). The Cognitive Interview: A meta-analytic review and study space analysis of the past 25 years. Psychology, Public Policy, and Law, 16, 340-372. https://doi.org/10.1037/a0020518

Merckelbach, H., \& Christianson, S. A. (2007). Amnesia for homicide as a form of malingering. In S. A. Christianson (Ed.), Offenders' memories of violent crimes (pp. 165-190). Wiley. https://doi.org/ 10.1002/9780470713082.ch7

Mitchell, K. J., \& Johnson, M. K. (2009). Source monitoring 15 years later: What have we learned from fMRI about the neural mechanisms of source memory? Psychological Bulletin, 135, 638-677. https://doi.org/10.1037/a0015849

Murre, J. M., \& Dros, J. (2015). Replication and analysis of Ebbinghaus' forgetting curve. PLoS One, 10, e0120644. https://doi.org/ 10.1371/journal.pone. 0120644

Newton, J. W., \& Hobbs, S. D. (2015). Simulating memory impairment for child sexual abuse. Behavioral Sciences \& the Law, 33, 407-428.

O'Connell, A. A. (1960). Amnesia and homicide. British Journal of Delinquency, 10, 262-276.

Otgaar, H., \& Baker, A. (2018). When lying changes memory for the truth. Memory, 22, 1-13. https://doi.org/10.1080/09658211.2017. 1340286

Otgaar, H., Howe, M. L., Patihis, L., Merckelbach, H., Lynn, S. J., Lilienfeld, S. O., \& Loftus, E. F. (2019). The return of the repressed: The persistent and problematic claims of longforgotten trauma. Perspectives on Psychological Science, 14, 1072-1095. https://doi.org/10.1177/1745691619862306

Parkin, A. J. (1999). Memory and amnesia: An introduction. Psychology Press. https://doi.org/10.4324/9780203765470

Parwatikar, S. D., Holcomb, W. R., \& Menninger, K. A. (1985). The detection of malingered amnesia in accused murderers. Journal of the American Academy of Psychiatry and the Law Online, 13, 97-103.

Pennington, N., \& Hastie, R. (1988). Explanation-based decision making: Effects of memory structure on judgment. Journal of Experimental Psychology: Learning, Memory, and Cognition, 14, 521.

Picknett, L., Prince, C. \& Prioir, S. (2001). Double standards: The Rudolf Hess cover-up. Little, Brown \& Company.

Porter, S., Birt, A. R., Yuille, J. C., \& Herve, H. F. (2001). Memory for murder: A psychological perspective on dissociative amnesia in legal contexts. International Journal of Law and Psychiatry, 24, 23-42. https://doi.org/10.1016/S0160-2527(00)00066-2

Pyszora, N. M., Barker, A. F., \& Kopelman, M. D. (2003). Amnesia for criminal offences: A study of life sentence prisoners. The Journal of Forensic Psychiatry, 14, 475-490. https://doi.org/10.1080/ 14789940310001599785

Riesthuis, P., Otgaar, H., Battista, F., \& Mangiulli, I. (2021). Public beliefs on the relationship between lying and memory. Psychology, Crime and Law, 1-24. https://doi.org/10.1080/1068316X. 2021.1929979
Roesch, R., \& Golding, S. L. (1986). Amnesia and competency to stand trial: A review of legal and clinical issues. Behavioral Sciences \& the Law, 4, 87-97. https://doi.org/10.1002/bs1.2370040107

Rogers, R., \& Bender, S. D. (2018). Clinical assessment of malingering and deception (4th ed.). The Guilford Press.

Romeo, T., Otgaar, H., Smeets, T., Landstrom, S., \& Boerboom, D. (2019). The impact of lying about a traumatic virtual reality experience on memory. Memory \& Cognition, 47, 485-495. https:// doi.org/10.3758/s13421-018-0885-6

Romeo, T., Otgaar, H., Smeets, T., Landström, S., \& Jelicic, M. (2018). The memory impairing effects of simulated amnesia for a mock crime. Applied Cognitive Psychology, 33, 983-990. https://doi. org/10.1002/acp.3508

Rubin, D. C., Feldman, M. E., \& Beckham, J. C. (2004). Reliving, emotions, and fragmentation in the autobiographical memories of veterans diagnosed with PTSD. Applied Cognitive Psychology, 18, 17-35. https://doi.org/10.1002/acp.950

Symons, C. S., \& Johnson, B. T. (1997). The self-reference effect in memory: A meta-analysis. Psychological Bulletin, 121, 371-394. https://doi.org/10.1037/0033-2909.121.3.371

Spinelli, M. G. (2001). A systematic investigation of 16 cases of neonaticide. American Journal of Psychiatry, 158, 811-813. https:// doi.org/10.1176/appi.ajp.158.5.811

Stout, R. G., \& Farooque, R. S. (2008). Claims of amnesia for criminal offenses: Psychopathology, substance abuse, and malingering. Journal of Forensic Sciences, 53, 1218-1222. https://doi.org/10. 1111/j.1556-4029.2008.00819.x

Sun, X., Punjabi, P. V., Greenberg, L. T., \& Seamon, J. G. (2009). Does feigning amnesia impair subsequent recall? Memory \& Cognition, 37, 81-89. https://doi.org/10.3758/MC.37.1.81

Tanay, E. (1969). Psychiatric study of homicide. American Journal of Psychiatry, 125, 1252-1258. https://doi.org/10.1176/ajp.125.9. 1252

Taylor, P. J., \& Kopelman, M. D. (1984). Amnesia for criminal offences. Psychological Medicine, 14, 581-588. https://doi.org/ $10.1017 /$ S003329170001518X

Tysse, J. E. (2005). Note: The right to an "imperfect" trial - amnesia, malingering, and competency to stand trial. William Mitchell Law Review, 32, 353.

Tysse, J. E., \& Hafemeister, T. L. (2006). Amnesia and the determination of competency to stand trial. Developments in Mental Health Law, 25, 65-80.

Van Oorsouw, K., \& Cima, M. (2007). The role of malingering and expectations in claims of crime-related amnesia. In S. A. Christianson (Ed.), Offenders' memories of violent crimes (pp. 191-213). Wiley. https://doi.org/10.1002/9780470713082.ch8

Van Oorsouw, K., \& Giesbrecht, T. (2008). Minimizing culpability increases commission errors in a mock crime paradigm. Legal and Criminological Psychology, 13, 335-344. https://doi.org/10. 1348/135532507x228539

Van Oorsouw, K., \& Merckelbach, H. (2006). Simulating amnesia and memories of a mock crime. Psychology, Crime \& Law, 12, 261-271. https://doi.org/10.1080/10683160500224477

Van Oorsouw, K., \& Merckelbach, H. (2004). Feigning amnesia undermines memory for a mock crime. Applied Cognitive Psychology, 18, 505-518. https://doi.org/10.1002/acp.999

Van Oorsouw, K. I. M., Merckelbach, H., Ravelli, D., Nijman, H., \& Mekking-Pompen, I. (2004). Alcoholic blackout for criminally relevant behavior. Journal of the American Academy of Psychiatry and the Law Online, 32, 364-370.

Wilson v. U.S. (1968). 391 F.2d 460 D.C. Cir.

Publisher's Note Springer Nature remains neutral with regard to jurisdictional claims in published maps and institutional affiliations. 